\title{
Assessment of cell proliferation in renal cell carcinoma using dual-phase ${ }^{18} \mathrm{~F}$-fluorodeoxyglucose PET/CT
}

\author{
REI ONISHI ${ }^{1}$, MASANORI NOGUCHI ${ }^{1,2}$, HAYATO KAIDA $^{3}$, FUKUKO MORIYA $^{4}$, KATSUAKI CHIKUI ${ }^{1}$, \\ SEIJI KURATA $^{3}$, AKIHIKO KAWAHARA ${ }^{4}$, MASAYOSHI KAGE ${ }^{4}$, MASATOSHI ISHIBASHI ${ }^{3}$ and KEI MATSUOKA ${ }^{1}$ \\ ${ }^{1}$ Department of Urology; ${ }^{2}$ Clinical Research Division, Research Center for Innovative Cancer Therapy; \\ ${ }^{3}$ Division of Nuclear Medicine, PET Center and Department of Radiology; ${ }^{4}$ Department of Pathology, \\ Kurume University School of Medicine, Kurume, Fukuoka 830-0011, Japan
}

Received July 25, 2014; Accepted April 8, 2015

DOI: $10.3892 / \mathrm{ol} .2015 .3372$

\begin{abstract}
The present study aimed to examine the association between ${ }^{18} \mathrm{~F}$-fluorodeoxyglucose $\left({ }^{18} \mathrm{~F}\right.$-FDG) uptake and cell proliferation markers; in addition, the correlation between ${ }^{18} \mathrm{~F}$-FDG uptake and biological characteristic in patients with renal cell carcinoma (RCC) was investigated using dual-phase ${ }^{18}$ F-FDG-positron emission tomography/computed tomography (PET/CT). Dual-phase ${ }^{18} \mathrm{~F}-\mathrm{FDG} \mathrm{PET} / \mathrm{CT}$ was performed on $31 \mathrm{RCC}$ patients and the maximum standardized uptake values at $1 \mathrm{~h}$ (SUV1) and $2 \mathrm{~h}$ (SUV2) as well as the retention index (RI; \%) in the primary tumors were calculated. Monoclonal antibodies for $\mathrm{Ki}-67$, minichromosome maintenance 2 (MCM2) and topoisomerase II $\alpha$ (topo II $\alpha$ ) were used to assess the expression levels of their respective proteins in excised tumor tissue using immunohistochemistry. The results demonstrated that RI and SUV2 in patients with Stage I/II + grade 1 (G1) RCC were significantly decreased compared with all patients with other stages/grades (RI, P=0.0065; SUV2, $\mathrm{P}=0.043)$; in addition, significantly increased uptake and RI were detected in patients with metastases compared with patients without metastases (SUV1, P=0.029; SUV2, $\mathrm{P}=0.0003$; $\mathrm{RI}, \mathrm{P}<0.001)$. All proliferation markers significantly correlated with RI (Ki-67, $\mathrm{r}=0.501, \mathrm{P}=0.004$; MCM2, $\mathrm{r}=0.359, \mathrm{P}=0.047$; topo II $\alpha, \mathrm{r}=0.402, \mathrm{P}=0.024$ ), while SUV1 and SUV2 correlated with Ki-67 only. In conclusion, the results of the present study demonstrated that dual-phase ${ }^{18} \mathrm{~F}-\mathrm{FDG}-\mathrm{PET} / \mathrm{CT}$ was more useful for predicting cell proliferation in $\mathrm{RCC}$ compared with single-phase imaging alone.
\end{abstract}

Correspondence to: Professor Masanori Noguchi, Clinical Research Division, Research Center for Innovative Cancer Therapy, Kurume University School of Medicine, 67 Asahi-machi, Kurume, Fukuoka 830-0011, Japan

E-mail: noguchi@med.kurume-u.ac.jp

Key words: renal cell carcinoma, ${ }^{18} \mathrm{~F}$-fluorodeoxyglucose, positron emission tomography/computed tomography, cell proliferation, Ki-67, minichromosome maintenance 2, topoisomerase II $\alpha$
However, follow-ups are required in order to determine whether dual-phase ${ }^{18} \mathrm{~F}$-FDG-PET/CT provides independent prognostic information.

\section{Introduction}

${ }^{18} \mathrm{~F}$-fluorodeoxyglucose $\left({ }^{18} \mathrm{~F}\right.$-FDG)-positron emission tomography (PET) is useful for evaluation of post-surgical recurrence and distant metastasis, therapeutic response to multikinase inhibitor in metastatic renal carcinoma, and prediction of prognosis for advanced renal cell carcinoma (RCC) (1-4). However, the utility of ${ }^{18} \mathrm{~F}$-FDG-PET for evaluating primary tumors is controversial. As the urinary tract is the major excretion route of ${ }^{18} \mathrm{~F}-\mathrm{FDG}$, high background activity may mask uptake by primary lesions; therefore, the sensitivity, specificity and accuracy for primary RCCs have been variable in previous studies $(1,5)$.

Tumor cell proliferation has been reported to correlate with tumor growth and patient prognosis (6). Commonly used immunohistochemical cell proliferation markers include Ki-67 antigen, minichromosome maintenance protein 2 (MCM2) and topoisomerase II $\alpha$ (topo II $\alpha$ ) (7-10). The Ki-67 antigen expression is indicative of the proportion of active cells throughout the cell cycle, which makes it an excellent marker for determining the growth fraction of cell populations (7). MCM2 is a superior marker to Ki-67 for assessment of the cell cycle, pathological factors and prognosis in RCC patients (8). Topo II $\alpha$ was reported to be a potential marker of anticancer agent efficacy; in addition, its marked expression in highly malignant RCCs suggests a potential therapeutic use for topo II $\alpha$ inhibitors $(9,10)$.

Correlations between tumor cell proliferation and ${ }^{18} \mathrm{~F}-\mathrm{FDG}$ uptake have been investigated in various malignant tumors (11). However, to the best of our knowledge, the association between tumor cell proliferation and ${ }^{18} \mathrm{~F}$-FDG uptake in RCC patients remains to be elucidated. The aim of the present study was to evaluate the association between ${ }^{18} \mathrm{~F}$-FDG uptake, cellular proliferation markers and tumor behavior in RCC patients.

\section{Materials and methods}

Patients. Eligibility for recruitment into the present study required a histological diagnosis of RCC. Clinical staging was performed using ${ }^{18} \mathrm{~F}$-FDG-PET/computed tomography (CT), 
magnetic resonance imaging (MRI), contrast-enhanced CT and ultrasound prior to surgery. Clinical and pathological staging (Stage I-IV) was based on the International Union Against Cancer 2009 tumor-node-metastasis (TNM) classification (12). Histopathological grading was determined on the basis of Fuhrman grade classification; grades $(\mathrm{G})$ ranged from G1-4 (13). All patients were required to undergo ${ }^{18}$ F-FDG-PET/CT for determining the clinical staging. Exclusion criteria included: An acute infection; a history of severe allergic reactions; pulmonary, cardiac or other systemic diseases; prior neoadjuvant targeted therapy; tumor size of $<10 \mathrm{~mm}$, due to the resolution limits of the PET/CT apparatus; and other inappropriate conditions for enrollment, as judged by clinicians. A total of 38 patients with suspected RCC underwent dual-phase ${ }^{18} \mathrm{~F}-\mathrm{FDG}-\mathrm{PET} / \mathrm{CT}$ prior to surgery at Kurume University Hospital between July 2011 and November 2012; RCC was confirmed in 31 of the 38 patients, who were subsequently enrolled in the present study. The study was conducted in accordance with the Declaration of Helsinki and approved by the Kurume University School of Medicine Ethics Committee (approval no. 11041; Kurume, Japan). All participants provided written informed consent prior to participating in the present study.

${ }^{18}$ F-FDG-PET/CT imaging acquisition. A Gemini-GXL 16 integrated full-ring PET/CT scanner (Philips Medical Systems, Inc., Cleveland, OH, USA) was used for data acquisition. Patients fasted for $4 \mathrm{~h}$ prior to ${ }^{18} \mathrm{~F}-\mathrm{FDG}$ injection; intake of sugar-free liquids was permitted. Prior to examination, the patients consumed $500 \mathrm{ml}$ water in order to enhance renal ${ }^{18} \mathrm{~F}$-FDG elimination. Prior to ${ }^{18} \mathrm{~F}-\mathrm{FDG}$ administration, 3-5 ml blood was drawn from medial cubital vein of patient, and blood glucose levels were measured with a blood glucose measuring instrument (One Touch Ultra Vue; Johnson \& Johnson, Tokyo, Japan). The median blood glucose level was $105 \mathrm{mg} / \mathrm{dl}$ (range, 78-119; normal range, 70-109). Patients were administered $0.12 \mathrm{mCi} / \mathrm{kg}{ }^{18} \mathrm{~F}-\mathrm{FDG}$ (median, $8.04 \mathrm{mCi}$; range, $4.80-9.88 \mathrm{mCi}$ ) via the antecubital vein. All patients rested quietly for a mean duration of $60.73 \pm 4.76 \mathrm{~min}$ (range, 50-74 min) between ${ }^{18} \mathrm{~F}$-FDG injection and whole-body imaging. Non-contrast whole-body full-dose CT scans were initially acquired, using the following parameters: $200 \mathrm{mAs}$; $120 \mathrm{kV} ; 0.75 \mathrm{sec} /$ tube rotation; slice thickness, $3 \mathrm{~mm}$; scan length, $940 \mathrm{~mm}$; and data acquisition time, 40 sec. CT scans were acquired during breath-holding in the expiratory phase. Immediately following CT acquisition, PET scans from the auditory meatus to the mid-thigh were acquired, with a time of 2 minutes 30 sec per cradle position using the three-dimensional acquisition mode. The total acquisition time was $30 \mathrm{~min}$. Images were reconstructed using the standard reconstruction protocol (14). Delayed imaging from the level of the liver to the kidneys was performed at a mean of $124.60 \pm 7.73 \mathrm{~min}$ (range, $110-138 \mathrm{~min}$ ) following the administration of ${ }^{18} \mathrm{~F}$-FDG using identical parameters.

${ }^{18}$ F-FDG PET/CT image analysis. A nuclear medicine physician with nuclear medicine experience of 17 years (Dr Hayato Kaida) and a nuclear medicine physician with 30 years of nuclear medicine experience (Professor Masatoshi Ishibashi) independently evaluated the whole-body PET/CT images for the presence of abnormally increased uptake in the kidney. Images were displayed on a Philips PET/CT workstation (Philips Medical Systems, Inc., Cleveland, OH, USA). A volume of interest (VOI) was placed over areas of abnormal uptake on axial images in order to calculate the maximum standardized uptake value (SUVmax) from the whole tumor. The VOI was drawn with reference to the ${ }^{18} \mathrm{~F}-\mathrm{FDG}-\mathrm{PET}$ image of PET/CT, CT image of PET/CT and contrast-enhanced CT or MRI. This was adjusted manually by visually inspecting the primary tumor outline in order to avoid overlapping with adjacent ${ }^{18} \mathrm{~F}$-FDG-avid structures or the interference of substances with physiological uptake, such as urine. The SUVmax (in $\mathrm{ng} / \mathrm{ml}$ ) of RCC-associated accumulation was calculated at $1 \mathrm{~h}$ (SUV1) and $2 \mathrm{~h}$ (SUV2) following the administration of ${ }^{18} \mathrm{~F}-\mathrm{FDG}$. The retention index (RI) was calculated as follows: RI $(\%)=[(\mathrm{SUV} 2-$ SUV1) / SUV1] x 100.

Immunohistochemistry. Patients underwent radical nephrectomy (35 cases), partial nephrectomy (2 cases) or biopsy (1 case), and resected specimens were routinely fixed in $10 \%$ formaldehyde and embedded in paraffin. Two tissue cores (diameter, $1 \mathrm{~mm}$; height, $5 \mathrm{~mm}$ ) were taken from the primary block for each sample to construct tissue microarrays (TMA), as previously described (15). Paraffin-embedded tissue samples were cut (3- $\mu \mathrm{m}$ thick) from the TMA blocks and incubated mouse monoclonal anti-Ki-67 (1:100; clone MIB-1; cat. no. M7240; Dako, Glostrup, Denmark), anti-MCM2 (1:400; clone BM28; cat. no. 610700; BD Transduction Laboratories, Lexington, KY, USA) and anti-topo II $\alpha$ (1:100; clone 3F6; cat. no. NCL-TOPO IIA; Novocastra, Newcastle, UK) primary antibodies overnight at $4^{\circ} \mathrm{C}$. The BenchMark ULTRA automated system (Ventana Medical Systems, Inc., Tucson, AZ, USA) was used for Ki-67 immunostaining. Briefly, each slide was heat-treated using a Ventana $\mathrm{CC} 1$ retrieval solution for $60 \mathrm{~min}$ at $95^{\circ} \mathrm{C}$, and then incubated with the Ki-67 antibody for $30 \mathrm{~min}$ at $37^{\circ} \mathrm{C}$. The automated system used the Ventana UltraView DAB detection kit with polyclonal goat horseradish peroxidase-conjugated secondary antibody with 3,3'diaminobenzidine (DAB) as the chromogen (Ventana iVIEW DAB detection kit; Ventana Medical Systems, Inc.). Next, each slide was incubated with secondary antibody for $30 \mathrm{~min}$ at $37^{\circ} \mathrm{C}$. Immunostaining for MCM2 and TOPII $\alpha$ were performed on the same, fully-automated Bond-Max System (Leica Microsystems, Ltd., Newcastle, UK) using onboard heat-induced antigen retrieval with epitope retrieval solution 2 (Leica Microsystems, Ltd.) for $30 \mathrm{~min}$ at $99^{\circ} \mathrm{C}$, and incubated with each antibody for $30 \mathrm{~min}$ at room temperature. This automated system used a Refine polymer Detection kit (Leica Microsystems, Ltd.) with horseradish peroxidase-conjugated polyclonal anti-mouse or rabbit IgG secondary antibody and DAB as the chromogen. The slides were incubated with secondary antibody for $30 \mathrm{~min}$ at room temperature, then visualized using DAB.

The immunohistochemical staining of Ki-67, MCM2 and topo II $\alpha$ was independently evaluated by two experienced observers without prior knowledge of the clinical parameters or patient conditions. Using a Provis AX80 microscope (Olympus Corporation, Tokyo, Japan), an average of 1,000 nuclei were counted per slide (magnification, x400): Labeling index $(\mathrm{LI} ; \%)=($ number of positive-staining nuclei/total number of cells counted) x 100 . 
Distant metastasis and follow up. When metastatic bone tumors were indicated by ${ }^{18} \mathrm{~F}-\mathrm{FDG}-\mathrm{PET} / \mathrm{CT}$, contrast-enhanced MRI and bone scintigraphy were performed to confirm bone metastasis. When liver tumors or lung metastasis were indicated by ${ }^{18} \mathrm{~F}$-FDG-PET/CT, these metastatic tumors were confirmed by contrast-enhanced abdominal CT and chest CT. Clinical/radiographic follow-up was performed every 3 months using CT or MRI.

Statistical analysis. Spearman's rank correlation test was performed to assess any association between dual-phase ${ }^{18}$ F-FDG-PET/CT parameters (SUV1, SUV2 and RI) and each cell proliferation marker (Ki-67, MCM2 and topo II $\alpha$ ). The Wilcoxon rank sum test was performed to compare the dual-phase ${ }^{18} \mathrm{~F}$-FDG-PET/CT parameters of tumor behavior (metastasis vs. without metastasis; Stage I/II+G1 vs. other stages/grades). Intra-class correlation coefficient (ICC) was obtained from the SUVmax of both early and delayed images and RI index to assess the intra- and inter-observer reproducibility by two nuclear physicians. Statistical analyses were performed using SAS software, version 9.3 (SAS Institute Inc., Cary, NC, USA). $\mathrm{P}<0.05$ was considered to indicate a statistically significant difference between values.

\section{Results}

Patient and tumor characteristics. Dual-phase ${ }^{18} \mathrm{~F}-\mathrm{FDG}$-PET/CT was performed on 38 patients with suspected primary RCC. Between July 2011 and November 2012, 37 of these patients underwent surgical resection. The remaining patient underwent a percutaneous core needle biopsy, as the RCC was Stage IV (clinical $\mathrm{T}_{4} \mathrm{~N}_{2} \mathrm{M}_{1}$ ); this patient was included in the present study, as the histopathological finding of RCC was obtained from all five biopsy sites. A total of 32 patients were pathologically diagnosed with RCC; 6 of the 38 patients had benign tumors (angiomyolipoma, $n=4$; cyst, $n=2$ ) and one patient with RCC was excluded from the present study, as they underwent neoadjuvant chemotherapy prior to surgery. In total, 31 patients (22 males and 9 females) were included in the study. The median age was 66 years (range, $41-88$ years). Eight patients had either solely distant metastases $(n=6)$ or both lymph node and distant metastases $(n=2)$. The majority of tumors were clear cell carcinoma $(n=26,84 \%)$. Patient and tumor characteristics are shown in Table I.

${ }^{18}$ F-FDG accumulation in RCC patients. The median SUV1 was $2.53 \mathrm{ng} / \mathrm{ml}$ [25th and 75th percentiles of the interquartile range (IQR), 1.92-3.49] and the median SUV2 was $2.32 \mathrm{ng} / \mathrm{ml}$ (IQR, 1.64-3.20). The median RI (\%) of all patients was -6.62 (IQR, -20.15-2.84). While SUV1 significantly correlated with SUV2 ( $\mathrm{r}=0.92, \mathrm{P}<0.001)$, it did not correlate with RI ( $\mathrm{r}=0.29$, $\mathrm{P}=0.11)$; however, $\mathrm{SUV} 2$ correlated with $\mathrm{RI}(\mathrm{r}=0.55, \mathrm{P}=0.001)$. The blinded intra- and inter-observer reliability analysis for the SUVmax and RI revealed intra-class correlation coefficients between readers of 0.93 (SUVmax of early image), 0.96 (SUVmax of delayed image) and 0.947 (RI), which were all significant $(\mathrm{P}<0.001)$.

Associations between tumor characteristics and ${ }^{18} \mathrm{~F}-\mathrm{FDG}$ uptake parameters. SUV1 and RI were compared between
Table I. Patient and tumor characteristics.

\begin{tabular}{|c|c|}
\hline Characteristic & $\mathrm{n}(\%)$ \\
\hline \multicolumn{2}{|l|}{ Gender } \\
\hline Male & $22(71.0)$ \\
\hline Female & $9(29.0)$ \\
\hline \multicolumn{2}{|l|}{ Pathological T stage } \\
\hline T1a & $15(48.0)$ \\
\hline $\mathrm{T} 1 \mathrm{~b}$ & $7(23.0)$ \\
\hline $\mathrm{T} 2$ & $3(10.0)$ \\
\hline $\mathrm{T} 3$ & $5(16.0)$ \\
\hline $\mathrm{T} 4$ & $0(0.0)$ \\
\hline $\mathrm{Tx}$ & $1(3.0)$ \\
\hline \multicolumn{2}{|l|}{ Metastasis status } \\
\hline Positive & $8(26.0)$ \\
\hline Negative & $23(74.0)$ \\
\hline \multicolumn{2}{|l|}{ Pathological stage } \\
\hline I & $19(61.0)$ \\
\hline II & $2(6.5)$ \\
\hline III & $2(6.5)$ \\
\hline IV & $8(26.0)$ \\
\hline \multicolumn{2}{|l|}{ Pathological type } \\
\hline Clear cell carcinoma & $26(84.5)$ \\
\hline Papillary carcinoma & $2(6.5)$ \\
\hline Chromophobe carcinoma & $1(3.0)$ \\
\hline Carcinoma of collecting duct & $1(3.0)$ \\
\hline Unclassified & $1(3.0)$ \\
\hline \multicolumn{2}{|l|}{ Fuhrman classification } \\
\hline G1 & $13(42.0)$ \\
\hline $\mathrm{G} 2$ & $16(53.0)$ \\
\hline G3 & $1(3.0)$ \\
\hline G4 & $1(3.0)$ \\
\hline
\end{tabular}

Median age of patients, 66 years (range, $41-88$ years); $n=31$. T, tumor; $\mathrm{G}$, grade; Tx, unknown pathological $\mathrm{T}$ stage (patient diagnosed by biopsy; no resection).

patients with $(n=8)$ and without metastases $(n=23)$, as well as between patients with Stage I/II+G1 lesions $(n=13)$ and other stages/grades $(n=18)$ (Fig. 1). SUV1 and SUV2 demonstrated significantly higher accumulation and RI showed a significantly higher value in the group with metastases compared with the group without metastases (SUV1, P=0.029; SUV2, $\mathrm{P}<0.001 ; \mathrm{RI}, \mathrm{P}<0.001)$. No significant difference in SUV1 was observed between patients with Stage I/II+G1 lesions and those with other stages/grades $(\mathrm{P}=0.14)$. However, RI and SUV2 were significantly lower in the Stage I/II+G1 group (RI, P=0.0065; SUV2, $\mathrm{P}=0.0432$ ).

Expression of cellular proliferation markers. The expression of the cellular proliferation-associated proteins Ki-67, MCM2 and topo II $\alpha$ was observed as dense immunostaining of the nucleus, whereas an absence of dense staining was observed in the cytoplasm and cell membrane. The median expression 
Table II. Association between cell proliferation markers and metastasis status.

\begin{tabular}{lccr}
\hline & \multicolumn{3}{c}{ Labelling index, \% } \\
\cline { 2 - 3 } Marker & Metastasis $(\mathrm{n}=8)$ & No metastasis $(\mathrm{n}=23)$ & $<0.001$ \\
\hline Ki-67 & $9.8(5.00-16.25)$ & $2.4(1.88-3.28)$ & $<.001$ \\
MCM2 & $80.0(55.00-90.00)$ & $15.0(5.00-36.25)$ & 0.003 \\
Topo II $\alpha$ & $6.5(1.30-11.50)$ & $0.9(0.10-2.25)$ & \\
\hline
\end{tabular}

Values are presented as the median with 25th and 75th percentiles of the IQR. IQR, interquartile range; MCM2, minichromosome maintenance 2 ; topo II $\alpha$, topoisomerase II $\alpha$.

A

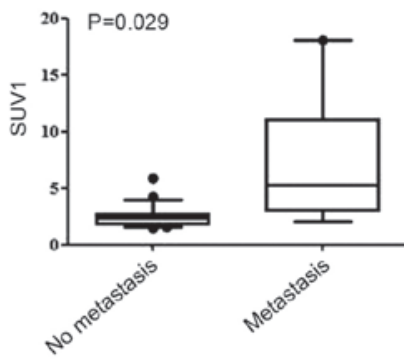

D

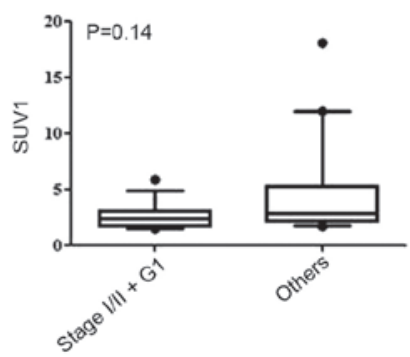

B

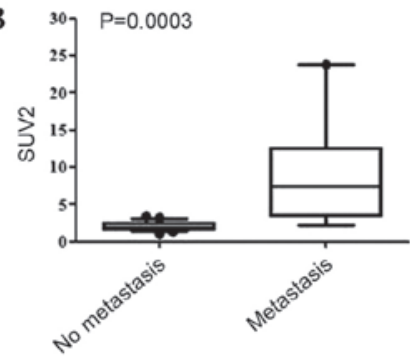

E

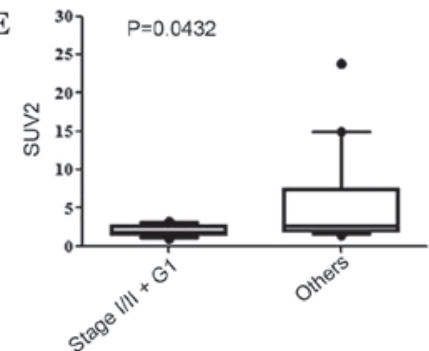

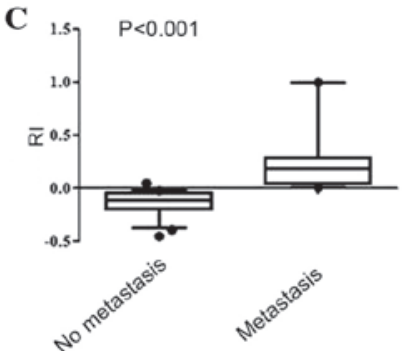

F

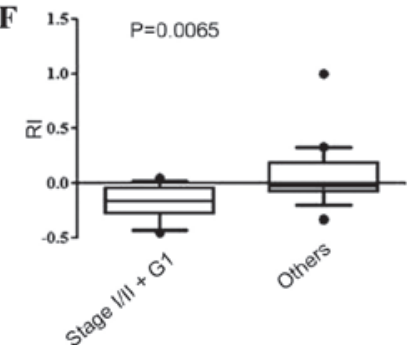

Figure $1 .{ }^{18} \mathrm{~F}$-fluorodeoxyglucose-positron emission tomography/computed tomography findings according to metastatic or pathological status. (A) SUV1, (B) SUV2 and (C) RI according to metastatic status in RCC patients. (D) SUV1, (E) SUV2 and (F) RI according to pathological status in RCC patients. Dots indicate raw values. SUV1/2, standardized uptake value at $1 / 2 \mathrm{~h}$; RI, retention index; G, grade.
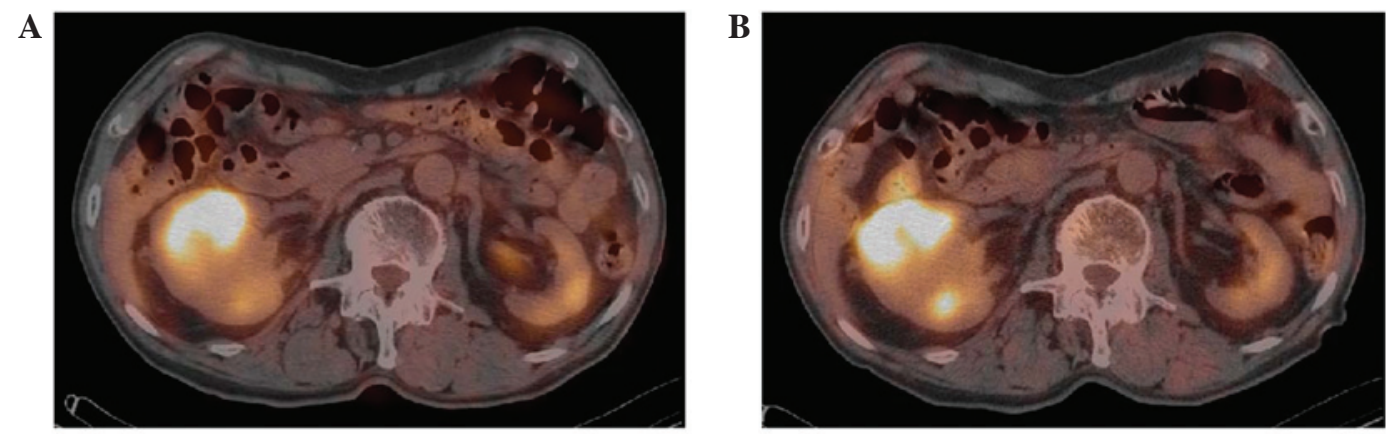

C

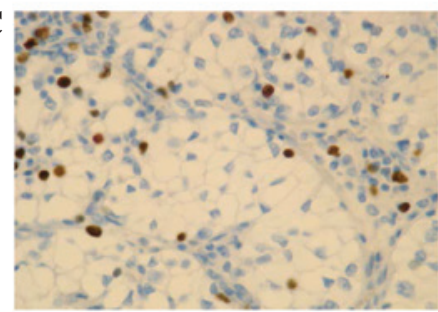

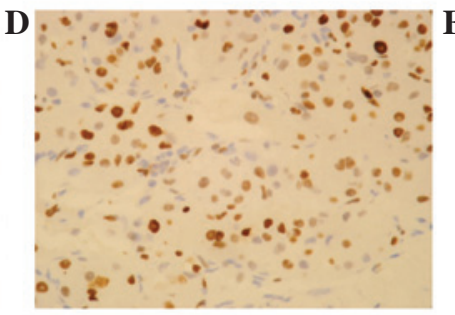

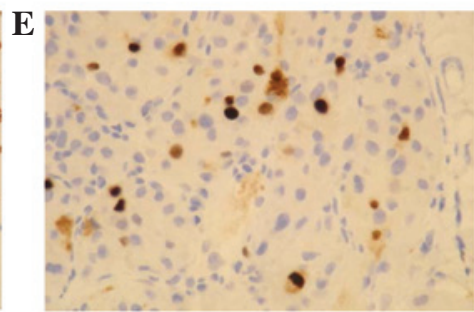

Figure 2. Representative images from a 79-year-old patients with renal cell carcinoma (pathological Tumor ${ }_{32}$ Node $_{0}$ Metastasis $_{1}$ ). ${ }^{18} \mathrm{~F}$-fluorodeoxyglucose-positron emission tomography/computed tomography: (A) SUV1, $11.97 \mathrm{ng} / \mathrm{ml}$; and (B) SUV2, $14.97 \mathrm{ng} / \mathrm{ml}$. The RI index was 25.06\%. Immunohistochemical analysis revealed potent expression of (C) Ki-67 (D) minichromosome maintenance 2 and (E) topoisomerase II $\alpha$. SUV1/SUV2, standardized uptake value at $1 / 2 \mathrm{~h}$. 
rates of $\mathrm{Ki}-67, \mathrm{MCM} 2$ and topo II $\alpha$, as measured by $\mathrm{LI}(\%)$, were 2.9 (IQR, 2.0-5.4), 30.0 (IQR, 10.0-65.0) and 1.6 (IQR, $0.1-3.2$, respectively. LI was significantly higher in patients with metastases compared with those without metastases (Ki-67, P<0.001; MCM2, P<0.001; and topo II $\alpha, \mathrm{P}=0.003$ ) (Table II).

Correlations between ${ }^{18} F-F D G$ uptake and cell proliferation markers expression. SUV1 demonstrated a significant positive correlation with Ki-67 LI ( $r=0.621, \mathrm{P}<0.001)$; however, no significant correlation was observed with MCM2 $(r=0.225$, $\mathrm{P}=0.22)$ or topo II $\alpha(\mathrm{r}=0.16, \mathrm{P}=0.38)$. SUV2 also had a significant positive correlation with $\mathrm{Ki}-67 \mathrm{LI}(\mathrm{r}=0.645, \mathrm{P}<0.001)$, although this was not correlated with MCM2 $(r=0.261$, $\mathrm{P}=0.15)$ or topo II $\alpha(\mathrm{r}=0.0175, \mathrm{P}=0.34)$. RI exhibited a significant positive correlation with all cell proliferation markers (LI: Ki-67, r=0.504, P=0.0038; MCM2, r=0.372, $\mathrm{P}=0.039$; topo II $\alpha, \mathrm{r}=0.412, \mathrm{P}=0.021)$. Representative ${ }^{18} \mathrm{~F}-\mathrm{FDG}-\mathrm{PET} / \mathrm{CT}$ and immunohistochemical staining results for Ki-67, MCM2 and topo II $\alpha$ expression in RCC patients are shown in Fig. 2 [results from one patient, aged 79 years: SUV1, $11.97 \mathrm{ng} / \mathrm{ml}$; SUV2, $14.97 \mathrm{ng} / \mathrm{ml}$; RI, 25.06; strong expression of Ki-67 (21.5\%), MCM2 (80.0\%) and topo II $\alpha$ $(12.8 \%)]$.

Distant metastasis. A total of eight patients had distant metastases, including bone metastasis $(n=5)$, lung metastasis $(n=3)$ and liver metastasis $(n=1)$, of which one patient had liver and bone metastases. The positive findings of ${ }^{18} \mathrm{~F}$-FDG uptake in bone metastasis were observed in all five patients and the positive finding of ${ }^{18} \mathrm{~F}$-FDG uptake in liver metastasis was observed in one patient. ${ }^{18} \mathrm{~F}-\mathrm{FDG} \mathrm{PET} / \mathrm{CT}$ revealed that one of the three suspected lung metastasis patients had ${ }^{18} \mathrm{~F}-\mathrm{FDG}$ avid metastatic lung tumors; however, these were not observed in the other two patients. Metastatic lung tumors were diagnosed by chest CT. One of the five suspected bone metastasis patients was confirmed to have bone metastasis through pathological procedure and MRI. The mean duration for clinical/radiographic follow-up was $640.5 \pm 258.7$ days (range, 246-1055 days). Mortality occurred in two of the eight patients due to metastatic tumor progression or local recurrence. Seven metastatic tumor patients were treated with molecular target therapy and five bone metastatic bone tumor patients were treated with radiotherapy, denosmab and bisphosphonate.

\section{Discussion}

The association between cancer cell proliferation and ${ }^{18} \mathrm{~F}-\mathrm{FDG}$ uptake has been reported in numerous solid malignancies (16-19). In addition, previous studies have investigated the association between $\mathrm{Ki}-67$ expression and ${ }^{18} \mathrm{~F}-\mathrm{FDG}$ uptake in cancer cells (20). The present study aimed to identify a correlation between two additional markers, MCM2 and topo II $\alpha$, and ${ }^{18} \mathrm{~F}-\mathrm{FDG}$ uptake in order to quantify the proliferation activity of cancer cells at all stages of the cell cycle. These three cell proliferation markers have previously been associated with tumor aggressiveness in RCC (21-23). In the current study, MCM2 demonstrated the highest expression of all proteins; in addition, its LI was significantly higher in patients with metastases for all proteins compared with patients without metastases, which supported previous findings $(8,21-23)$. Dual-phase imaging is reported to improve the lesion-to-background ratio due to a gradual decrease in background activity $(24,25)$. Aide et al (25) noted higher lesion-to-background contrast on delayed images in an RCC patient. Wahl et al (26), using a nude mouse model, reported that the tumor-to-background ratio increased continuously with time. Therefore, dual-phase scans in the present study were performed based on these past reports.

In the current study, SUV1 and SUV2 were found to be significantly correlated with $\mathrm{Ki}-67$ expression, although they did not correlate with MCM2 and topo II $\alpha$ expression. By contrast, RI significantly correlated with Ki-67, MCM2 and topo II $\alpha$ expression. Wong et al (27) reported that ${ }^{18} \mathrm{~F}-\mathrm{FDG}$ and 3-Deoxy-3-[ $\left.{ }^{18} \mathrm{~F}\right]$-fluorothymidine uptake were significantly correlated with $\mathrm{Ki}-67$ expression and that ${ }^{18} \mathrm{~F}-\mathrm{FDG}$ uptake in RCC was associated with cell proliferation. The results of the present study demonstrated that SUV1 was correlated with Ki-67 expression; these findings are in agreement with previous studies which reported that SUV1 was correlated with glucose transporter (GLUT)-1 expression and SUV2 correlated with GLUT-1 as well as hexokinase (HK-II) expression (28-30). RI is linked with HK-II expression and is a known marker of phosphorylation (28). The current study found that SUV1 significantly correlated with SUV2, but not with RI; in addition, SUV2 correlated with RI. Therefore, in RCC, HK-II expression may be associated with SUV2 but not with SUV1. All eight cases with distant metastases had increases in RI. In addition, RI correlated with Ki-67 expression, Topo II $\alpha$ and MCM2, whilst SUV1 and SUV2 correlated with $\mathrm{Ki}-67$ expression alone, suggesting that RI may be more useful for predicting cell proliferation of RCC than SUVmax. A previous study reported that RI is linked with hexokinase expression and that RI is a marker of phosphorylation (28). These data indicate that hexokinase and phosphorylation rate may be more closely associated with cell proliferation in RCC. However, immunohistochemical staining of hexokinase was not performed in the present study, and the relationship between RI and hexokinase expression should be investigated in the future.

In the present study, the SUV2 and RI of patients with metastases were significantly higher compared with those patients without metastases. The SUV2 and RI of the patients with Stage I/II+G1 lesions were significantly lower compared with patients with other stages/grades; however, SUV1 was not significantly altered. Ozülker et al (31) suggested that the Fuhrman grade of ${ }^{18} \mathrm{~F}$-FDG uptake-positive patients was increased compared with that of ${ }^{18} \mathrm{~F}$-FDG uptake-negative RCC patients (31). Ho et al (32) reported that the SUVmax in high-grade RCCs was higher compared with that in low-grade tumors. In the present study, the SUV2 values of eight patients with distant metastases were significantly higher than the SUV1 values, suggesting a link between tumor behavior and SUV2 or RI. This therefore indicated that SUV2 and RI may reflect tumor aggressiveness more accurately than SUV1.

The association between RI and cell proliferation markers or tumor behavior has been investigated in previous studies. In malignant lymphoma, dual-phase ${ }^{18} \mathrm{~F}-\mathrm{FDG}-\mathrm{PET} / \mathrm{CT}$ was reported to be useful for predicting cell proliferation due to 
its significant correlation with Ki-67 expression and RI (33). In breast cancer patients, RI was demonstrated to be more closely associated with biologic and clinical parameters, including Ki-67 expression, histologic grade and Her-2 expression, compared with SUVmax (34). RI may therefore be a useful marker for predicting cell proliferation and clinicopathological factors.

The mechanism of ${ }^{18} \mathrm{~F}$-FDG uptake by RCC is controversial. Aide et al (25) suggested that ${ }^{18} \mathrm{~F}-\mathrm{FDG}$ uptake by RCC may be associated with tumor size, but not with tumor grade. The present data suggested that tumor cell proliferation may contribute to ${ }^{18} \mathrm{~F}$-FDG uptake in RCC; however, further investigation is required.

There are certain limitations in the present study. The number of RCC patients included in the study was small; however, to the best of our knowledge, previous studies regarding dual-phase ${ }^{18}$ F-FDG-PET imaging in RCC patients were also limited. Aide et al (25) used only one case and Ozülker et al (31) used 18 cases. Therefore, the present study has an increased number of RCC patients compared with these previous studies and was the first to research the association between RI and certain cell proliferation markers. In addition, the associations between practical prognosis and RI or cell proliferation markers have not been investigated. The association between prognosis of RCC and ${ }^{18} \mathrm{~F}$-FDG uptake have been previously reported (35); however, the association between the prognosis and ${ }^{18} \mathrm{~F}-\mathrm{FDG}$ uptake in addition to cell proliferation markers have not been investigated. If the prognosis of RCC patients may be predicted using RI and cell proliferation markers, the resultant data may have an impact on the management of therapy in RCC patients. The analysis of the prognosis of RCC using RI and cell proliferation markers should therefore be further investigated in a larger population of RCC patients.

In conclusion, dual-phase ${ }^{18} \mathrm{~F}-\mathrm{FDG}-\mathrm{PET} / \mathrm{CT}$ is more useful for predicting cell proliferation in RCC compared with single-phase imaging alone. In addition, RI is a noninvasive and useful marker for predicting cell proliferation and tumor behavior in preoperative RCC patients.

\section{Acknowledgements}

The present study was supported, in part, by Grants-in-Aid (KAKENHI) of the Ministry of Education, Culture, Sports, Science and Technology of Japan (no. 22591782 to Professor Masanori Noguchi, Department Urology, Clinical Research Division, Research Center for Innovative Cancer therapy, Kurume University School of Medicine).

\section{References}

1. Lawrentschuk N, Davis ID, Bolton BM and Scott AM: Functiona imaging of renal cell carcinoma. Nat Rev Urol 7: 258-266, 2010.

2. Kumar R, Shandai V, Shamim SA, Jeph S, Singh H and Malhotra A: Role of FDG PET-CT in recurrent renal cell carcinoma. Nucl Med Commun 31: 844-850, 2010.

3. Minamimoto R, Nakaigawa N, Tateishi U, et al: Evaluation of response to multikinase inhibitor in metastatic renal cell carcinoma by FDG PET/contrast-enhanced CT. Clin Nucl Med 35: 918-923, 2010.

4. Namura K, Minamimoto R, Yao M, Makiyama K, et al: Impact of maximum standardized uptake value (SUVmax) evaluated by 18 -Fluoro-2-deoxy-D-glucose positron emission tomography/computed tomography (18F-FDG-PET/CT) on survival for patients with advanced renal cell carcinoma: A preliminary report. BMC Cancer 10: 667, 2010.
5. Wang HY, Ding HJ, Chen JH, et al: Meta-analysis of the diagnostic performance of [18F]FDG-PET and PET/CT in renal cell carcinoma. Cancer Imaging 12: 464-474, 2012.

6. Mitsudomi T, Hamajima N,Ogawa M and Takahashi T: Prognostic significance of p53 alterations in patients with non-small cell lung cancer: A meta-analysis. Clin Cancer Res 6: 4055-4063, 2000.

7. Gerdes J, Schwab U,Lemke H and Stein H: Production of a mouse monoclonal antibody reactive with a human nuclear antigen associated with cell proliferation. Int J Cancer 31: 13-20, 1983.

8. Rodins K, Cheale M, Coleman N and Fox SB: Minichromosome maintenance protein 2 expression in normal kidney and renal cell carcinomas: Relationship to tumor dormancy and potential clinical utility. Clin Cancer Res 8: 1075-1081, 2002.

9. Gianni L, Norton L, Wolmark N, Suter TM, Bonadonna G and Hortobagyi GN: Role of anthracyclines in the treatment of early breast cancer. J Clin Oncol 27: 4798-4808, 2009.

10. Albadine R, Wang W, Brownlee NA, et al: Topoisomerase II alpha status in renal medullary carcinoma: Immune-expression and gene copy alterations of a potential target of therapy. J Urol 182: 735-740, 2009.

11. Murakami S, Saito H, Sakuma Y, Mizutani Y, et al: Correlation of $18 \mathrm{~F}$-fluorodeoxyglucose uptake on positron emission tomography with $\mathrm{Ki}-67$ index and pathological invasive area in lung adenocarcinomas $30 \mathrm{~mm}$ or less in size. Eur J Radiol 75: e62-e66, 2010.

12. Sobin LH, Gospodarowicz MK and Wittekind CH (Eds); International Union Against Cancer: TNM Classification of Malignant Tumors. 7th edition. Wiley-Blackwell, Baltimore, MD, pp253-257, 2009.

13. Fuhrman SA, Lasky LC and Limas C: Prognostic significance of morphologic parameters in renal cell carcinoma. Am J Pathol 6: 655-663, 1982.

14. Groheux D, Martineau A, Vrigneaud JA, et al: Effect of variation in relaxation parameter value on LOR-RAMLA reconstruction of 18F-FDG PET studies. Nucl Med Commun 30: 926-933, 2009.

15. Noguchi M, Yao A, Harada M, et al: Immunological evaluation of neoadjuvant peptide vaccination before radical prostatectomy for patients with localized prostate cancer. Prostate 67: 933-942, 2007.

16. Dooms C, van Baardwijk A, Verbeken E, et al: Association between 18F-fluoro-2-deoxy-d-glucose uptake values and tumor vitality: Prognostic value of positron emission tomography in early stage non-small cell lung cancer. J Thorac Oncol 4: 822-828, 2009.

17. Folpe AL, Lyles RH, Sprouse JT, Conrad EU III and Eary JF: (F-18) fluorodeoxyglucose positron emission tomography as a predictor of pathologic grade and other prognostic variables in bone and soft tissue sarcoma. Clin Cancer Res 6: 1279-1287, 2000.

18. Watababe Y, Suefuji H, Hirose Y, et al: 18F-FDG uptake in primary gastric malignant lymphoma correlates with glucose transporter-1 and histologic malignant potential. Int J Hematol 97: 43-49, 2013.

19. Kim BS and Sung SH: Usefulness of 18F-FDG uptake with clnicopathological and immunohistochemical prognostic factors in breast cancer. Ann Nucl Med 26: 175-183, 2012.

20. Nguyen XC, Lee WW, Chung JH, et al: FDG uptake, glucose transporter type 1, and Ki-67 expressions in non-small cell lung cancer: Correlations and prognostic values. Eur J Radiol 62: 214-219, 2007.

21. Dekel Y, Frede T, Kugel V, Neumann G, Rassweiler J and Koren R: Human DNA topoisomerase II-alpha expression in laparoscopically treated renal cell carcinoma. Oncol Rep 14: 271-274, 2005.

22. Kankuri M, Söderström K, Pelliniemi T, Vahlberg T, Pyrhönen S and Salminen E: The association of immunoreactive P53 and Ki-67 with T-stage, grade, occurrence of metastases and survival in renal cell carcinoma. Anticancer Res 26: 3825-3833, 2006.

23. Dudderidge TJ, Stoeber K, Loddo M, et al: Mcm 2, Geminin, and Ki-67 define proliferative state and are prognostic markers in renal cell carcinoma. Clin Cancer Res 11: 2510-2517, 2005.

24. Cheng G, Torigian DA, Zhuang $\mathrm{H}$ and Alavi A: When should we recommend use of dual time-point and delayed time-point imaging techniques in FDG-PET? Eur J Nucl Med Mol Imaging 40: 779-787, 2013.

25. Aide N, Cappele O, Bottet P, et al: Efficiency of [18F] FDG PET in characterizing renal cancer and detecting distant metastases: A comparison with CT. Eur J Nucl Med Mol Imaging 30: 1236-1245, 2003.

26. Wahl RL, Harney J, Hutchins G and Grossman HB: Imaging of renal cancer using positron emission tomography with 2-deox-2-(18-F)-fluoro-D-glucose: Pilot animal and human studies. J Urol 146: 1470-1474, 1991.

27. Wong PK, Lee ST, Murone C, et al: In vivo imaging of cellular proliferation in renal cell carcinoma using $18 \mathrm{~F}$-fluorothymidine PET. Asia Oceania J Nucl Med Biol 2: 3-11, 2014. 
28. Higashi T, Saga T, Nakamoto Y, et al: Relationship between retention index in dual phase 18F-FDG PET and hexokinase-II and glucose transporterl expression in pancreatic cancer. J Nucl Med 43: 173-180, 2002.

29. Zhao S, Kuge Y, Mochizuki T, et al: Biologic correlates of intratumoral heterogeneity in $18 \mathrm{~F}-\mathrm{FDG}$ distribution with regional expression of glucose transporters and hexokinase-II in experimental tumor. J Nucl Med 46: 675-682, 2005.

30. Waki A, Kato H, Yano R, et al: The importance of glucose transporter activity as the rate-limiting step of 2-deoxygluoce uptake in tumors cells in vitro. Nucl Med Biol 25: 593-597, 1998.

31. Ozülker T, Ozülkar F, Ozbek E and Ozpaçaci T: A prospective diagnostic accuracy study of F-18 fluorodeoxyglucose-positron emission tomography/computed tomography in the evaluation of indeterminate renal masses. Nucl Med Commun 32: 265-272, 2011.
32. Ho CL, Chen S, Ho KM, et al: Dual-tracer PET/CT in renal angiomyolipoma and subtypes of renal cell carcinoma. Clin Nucl Med 37: 1075-1082, 2012.

33. Chang CC, Cho SF, Chen YW, Tu HP, Lin CY and Chang CS: SUV on dual-phase FDG PET/CT correlates with the Ki-67 proliferation index in patients with newly diagnosed non-Hodgkin lymphoma. Clin Nucl Med 37: e189-e195, 2012.

34. García Vicente AM, Castrejón ÁS, Relea Calatayud F, Muñoz AP, León Martín AA, López-Muñiz IC, et al: 18F-FDG retention index and biologic prognostic parameters in breast cancer. Clin Nucl Med 37: 460-466, 2012.

35. Ferda J, Ferdova E, Hora M, Hes O, Finek J, Topolcan O and Kreuzberg B: 18F-FDG-PET/CT in potentially advanced renal cell carcinoma: A role in treatment decisions and prognosis estimation. Anticancer Res 33: 2665-2672, 2013. 